DOI 10.2478/aucft-2014-0013

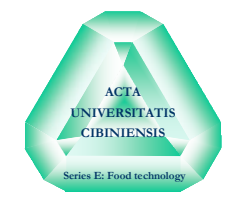

\title{
ANALYTICAL METHOD FOR DIFFERENTIATION OF CHILLED AND FROZEN-THAWED CHICKEN MEAT
}

\author{
Ivelina IVANOVA*, Galin IVANOV***1, Vasil SHIKOV**, Snezhana \\ IVANOVA*** \\ *Department of Analytical chemistry, Technological Faculty, University of \\ Food Technologies, Plovdiv, Bulgaria \\ **Department of Food Preservation and Refrigeration Technology, \\ Technological Faculty, University of Food Technologies, Plovdiv, Bulgaria \\ ***Department of Catering Technology and Tourism, Faculty of Economics, \\ University of Food Technologies, Plovdiv, Bulgaria
}

\begin{abstract}
Chilled and frozen chicken breast and thigh meat were stored at $+4 \pm 1 \mathrm{oC}$ and $20 \pm 1 \mathrm{oC}$, respectively. Maillard reaction between ribose and meat proteins of the chicken samples was initiated. The changes in the ribose-induced Maillard reaction rate during chilled and frozen storage of chicken meat were evaluated on the bases of corrected absorbance values (A420*) and bovine melanoidin equivalent values (mg BME/g). Application of BME as a measure of ribose-induced Maillard reaction rate enables comparability of the data obtained by different spectrophotometers. It was found that the BME values of chicken meat frozen stored for more than 15 days were significantly $(\mathrm{P}<0.05)$ lower than BME values of chilled-stored samples. According to the suggested threshold limit values the chicken thigh and breast meat with BME values lower than $30 \mathrm{mg} \mathrm{BME} / \mathrm{g}$ and 51 $\mathrm{mg} \mathrm{BME/g,} \mathrm{respectively} \mathrm{could} \mathrm{be} \mathrm{classified} \mathrm{as} \mathrm{frozen-thawed.}$
\end{abstract}

Keywords: melanoidins, chicken meat, chilling, freezing, differentiation

\section{INTRODUCTION}

The refrigeration treatment is one of the most effective means for extending meat shelf life. Furthermore, refrigeration preserves to the greater extend

1 Corresponding author. Mailing address: Associated professor PhD Galin Ivanov, Department of Food Preservation and Refrigeration Technology, Technological Faculty, University of Food Technologies, 26 Maritza blvd., 4002, Plovdiv, Bulgaria. E-mail: ivanovgalin@yahoo.com

Vol. 18 (2014), no. 2 
meat native quality in comparison with the other preservation method as heating, drying, smoking etc. Chilled meat is perishable food stuff and deteriorates progressively throughout its life. For extending shelf life, meat has to be frozen and maintained at temperatures below $-18^{\circ} \mathrm{C}$ (Jeremiah, 1996). However, while frozen storage is effective in protecting against microbiological deterioration of meat, its organoleptic properties suffer (Farrant et al., 1967). During the freezing process ice crystals formation is initiated. One consequence of the formation of ice crystals is physical damage to the microstructures, which continues throughout frozen storage and thawing due to a continuous recrystallization (Martino and Zaritzky, 1988). Moreover, meat on thawing loses exudate and thus the substances, which add the characteristic flavor and nutritional value to meat, are partially lost. The texture of meat is also affected by the formation of ice crystals, which damages the muscle structure.

It is well know that freezing causes greater changes in meat structure and overall quality than chilling. That's why frozen-thawed meat could not meet the quality parameters of fresh chilled meat (Šimoniová et al., 2013). Because of its lower market price, frozen meat is often sold as chilled meat. Adequate analytical methods for determination of fresh chilled vs. thawed meat are needed for ensuring fair-trading and to enable consumers to make informed choices. Such analytical methods most often referred to in the literature are: enzymatic, DNA based, spectroscopic, bioimaging and sensory methods (Ballin and Lametsch, 2008). However, most of these methods are only reliable for whole meat but not for minced meat. On the other hand, these methods require scientific instruments and qualified personnel which would reduce the availability for many industries (Ballin and Lametsch, 2008).

Tan et al. (2013) proposed an alternative method to distinguish fresh and frozen-thawed meat based on the Maillard reaction between meat proteins and ribose, yielding brown pigments (melanoidins). An absorbance of the obtained water soluble extracts was measured and converted into a freshness index $\left(\mathrm{A}_{420} *\right)$. The authors reported for lower freshness index of frozenthowed in comparison with fresh meat, which was explained with the biochemical degradation of meat proteins resulting in reduced capability to react with ribose. However, further investigations need to be carried out in order to validate the use of the suggested method.

The main disadvantage of the method mentioned above is the absence of the analytical standard for melanoidins formed as a result of the Maillard reaction between proteins of meat and ribose. Such standard could be used as Maillard reaction rate equivalent. Application of melanoidin equivalent Acta Universitatis Cibiniensis Series E: FOOD TECHNOLOGY

Vol. 18 (2014), no. 2 
standard will enable comparability of the results obtained by different spectrophotometers and from different laboratories, which is necessary for practical implementation of the method. Furthermore, the changes in the rate of the Maillard reaction between meat proteins and ribose during chilled and frozen meat storage must be investigated in order to found the threshold limit values (TLV) of the standard melanoidin equivalent enabling differentiation of chilled and frozen-thawed meat. For the reliability of the method it is important to demonstrate that during the whole storage period of chilled and frozen meat the standard melanoidin equivalent values will be significantly different. In addition the effect of chicken muscles type (light and dark meat) on the rate of the Maillard reaction between meat proteins and ribose should be investigated.

The aim of the present study was to develop analytical method for differentiation of chilled and frozen-thawed chicken meat on the basis of the standard melanoidin equivalent values as Maillard reaction rate criterion.

\section{MATERIALS AND METHODS}

\section{Meat samples and refrigeration treatment}

Three batches of chicken breast and thigh meat were delivered from local processor. All samples were at twenty four hours postmortem. The chicken breast and thigh meat samples were analyzed immediately after delivering (fresh chicken meat) and after refrigeration treatment according to the experimental design shown in Figure 1.

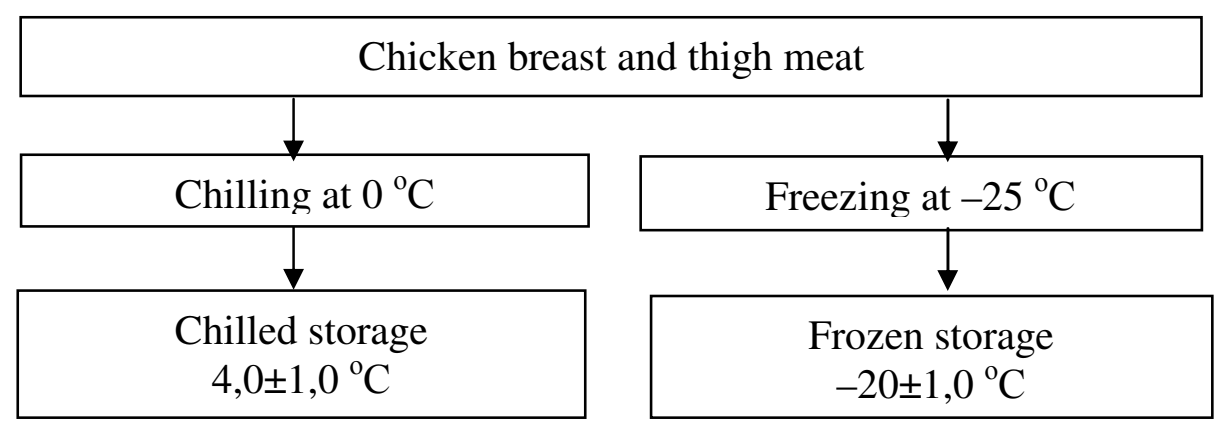

Figure 1. Refrigeration treatment of the test samples.

Chemical composition of the chicken breast and thigh meat was determined at the beginning of the experiment according to the standard analytical methods. Samples for Maillard reaction and sensory evaluation tests were taken at the beginning of the experiment (day 1) and on the 1, 4, 5, 6, 7, 8

Vol. 18 (2014), no. 2 
and 9 day for chilled stored samples, and on the 1, 4, 5, 6, 7, 8, 9, 10, 30, 60, 90 and 180 day for frozen stored samples. All frozen samples were thawed at $8{ }^{\circ} \mathrm{C}$ for $3 \mathrm{~h}$ before analyses.

\section{Physicochemical analysis}

Moisture content was determined by sample heating at $105{ }^{\circ} \mathrm{C}$ to constant weight according to the standard methods (AOAC, 1980). Ash content was determined by mineralization of meat as described in AOAC (1980). Protein content in meat sample was determined according to the standard method of Kieldahl (AOAC, 1980) with automatic analysis on UDK 152 (VELP SCIENTIFICA, Italia). Determination of total lipids content was performed by method of Bligh and Dyer (1959). $\mathrm{pH}$ value was determined potentiometrically according to Korkeala et al. (1986) by using of $\mathrm{pH}$ meter pH211 (HANNA instruments).

\section{Evaluation of ribose-induced Maillard reaction rate}

Induction of Maillard reaction on chicken meat and extraction of watersoluble melanoidins were carried out according to the procedure described by Tan et al. (2013) with some modifications. Chicken breast and thigh meat samples were minced and manually mixed $(10 \%$, w/w) with D-ribose (Sigma-Aldrich Chemie $\mathrm{GmbH}$ ). Eleven grams of the ribose-minced meat mixtures were heated at $95{ }^{\circ} \mathrm{C}$ for $60 \mathrm{~min}$ in a thermostat UH 8 (VEB MLW Prüfgeräte-Werk, Medingen, Germany). After finishing the heating procedure ribose-minced meat mixture was immediately cooled in ice water and ground to obtain homogenous powder. Extraction procedure described by Tan et al. (2013) was fallowed. Control was carried out in a similar manner with substitution of ribose with sucrose. The absorbance of watersoluble extracts at $420 \mathrm{~nm}$ and $550 \mathrm{~nm}$ was measured with UV-VIS spectrophotometer Helios Omega (Termo Scientific). The corrected absorbance values (A420*) were calculated as described by Tan et al. (2013). Isolation of bovine melanoidins was performed according to certified method for determination of melanoidins in meat and meat products (Authors Certificate № 34155, priority of 31.05.1982, INRA, Sofia). The procedure described by Obretenov et al. (1993) was fallowed. Isolated melanoidins powder was used for preparation of standard curve (Figure 2). Bovine melanoidin equivalent values for $1 \mathrm{~g}$ chicken meet sample (mg BME/g) were calculated on the basis of the corrected absorbance values (A420*) by using the standard curve shown in Figure 2.

Acta Universitatis Cibiniensis Series E: FOOD TECHNOLOGY

Vol. 18 (2014), no. 2 


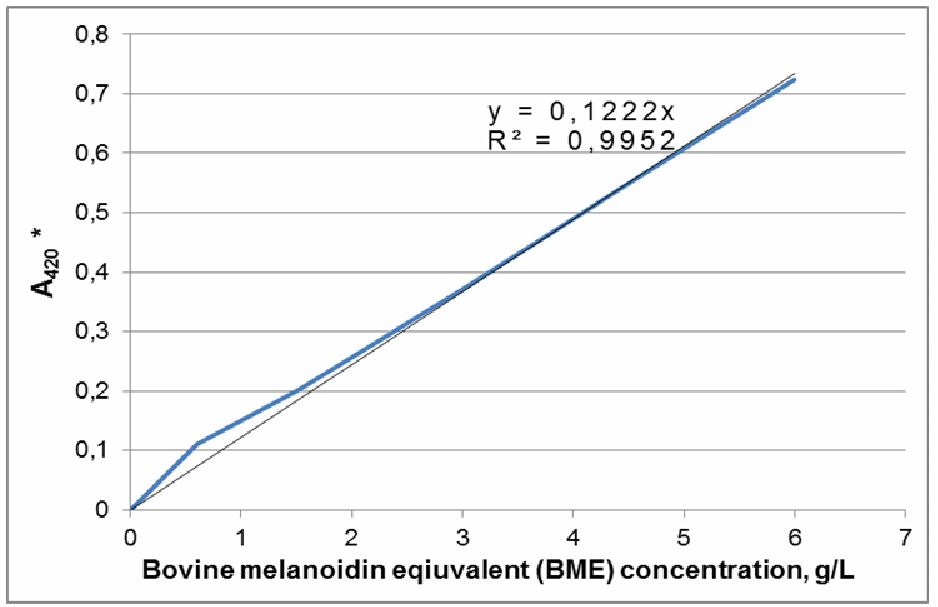

Figure 2. Standard curve for BME calculation

\section{Sensory evaluation}

Sensory quality of all studied samples was evaluated by five member expert panel. The color, appearance, texture and aroma acceptability of chicken breast and thigh samples were evaluated. According to the results from sensory evaluation, test samples were classified as acceptable (satisfactory sensory quality), with first signs of deterioration (undesirable changes in color and appearance) or deteriorated (unacceptable sensory characteristics).

\section{Statistical analysis}

Statistical analyses were carried out on the averages of the triplicate results. Data were analyzed by the analysis of variance (one-way ANOVA) method with a significant level of $\mathrm{P} \leq 0.05$ (Draper and Smith, 1998). The Duncan's multiple comparison test (SPSS) with a significant difference set at $\mathrm{P} \leq 0.05$ was used to compare sample means. Significant differences between means less than 0.05 were considered statistically significant (Kenward, 1987). All statistical procedures were computed using the Microsoft Excel 5.0 software.

\section{RESULTS AND DISCUSSIONS}

\section{Chemical composition}

The data for chemical composition and $\mathrm{pH}$ of the experimental chicken breast and thigh samples are presented in Table 1.

Acta Universitatis Cibiniensis Series E: FOOD TECHNOLOGY

Vol. 18 (2014), no. 2 
Table 1. Physicochemical composition of the studies batches of chicken meat

\begin{tabular}{|c|c|c|c|c|c|}
\hline \multirow{2}{*}{ Batch } & \multicolumn{5}{|c|}{ Chicken breast samples } \\
\cline { 2 - 6 } & Moisture, \% & Protein, \% & Lipid, \% & Ash, \% & $\mathrm{pH}$ \\
\hline Batch 1 & 72,05 & 22,31 & 1,13 & 1,27 & 6,12 \\
\hline Batch 2 & 71,87 & 22,45 & 1,21 & 1,30 & 6,15 \\
\hline Batch 3 & 71,45 & 22,78 & 1,26 & 1,22 & 6,20 \\
\hline Batch & \multicolumn{5}{|c|}{ Chicken thigh samples } \\
\cline { 2 - 6 } & Moisture, \% & Protein, \% & Lipid, \% & Ash, \% & $\mathrm{pH}$ \\
\hline Batch 1 & 78,35 & 18,65 & 4,22 & 1,08 & 6,22 \\
\hline Batch 2 & 78,66 & 18,36 & 3,96 & 0,97 & 6,25 \\
\hline Batch 3 & 78,12 & 18,08 & 4,41 & 1,02 & 6,27 \\
\hline
\end{tabular}

There were no significant $(\mathrm{P}<0.005)$ differences in the physiochemical characteristics of the samples from the different batches. Probably this is due to the same breed of chickens (broiler) and the similar conditions of feeding. It is evident that thigh and breast meat had similar moisture and ash contents. Protein content of breast muscles was significantly $(\mathrm{P} \leq 0.05)$ higher and fat content was significantly $(\mathrm{P} \leq 0.05)$ lower than the thigh muscles. The $\mathrm{pH}$ values of breast meat were slightly lower in comparison with thigh meat.

Changes in the ribose-induced Maillard reaction rate during chilled and frozen storage of chicken meat

The changes of the corrected absorbance values (A420*) of chicken breast and thigh meat samples during chilled and frozen storage are presented on Figure 3. Simultaneously, sensory evaluation of all studied samples was performed. Results obtained (Figure 3) showed that breast meat samples had higher A420* values than thigh samples. This fact could be explained with the higher protein content of chicken breast meat (Table 1) enabling increased Maillard reaction rate. These results are in agreement with the finding of Tan et al. (2012), who established higher A420* values of chicken in comparison with pork meat.

However, the A 420 * values of chicken breast and thigh meat indicated, that the muscle type has significant effect on the ribose-induced Maillard reaction rate and has to be considered when using for meat quality evaluation.

It was found that $\mathrm{A} 420$ * values decreased significantly $(\mathrm{P}<0.05)$ during the first 6 days of chilled storage and 30 days of frozen storage of chicken meat samples. This tendency is also in agreement with the findings of Tan et al.

Vol. 18 (2014), no. 2 
(2013). However, a rapid increase in A420* values of chilled breast meat after 6-th day of storage was found.
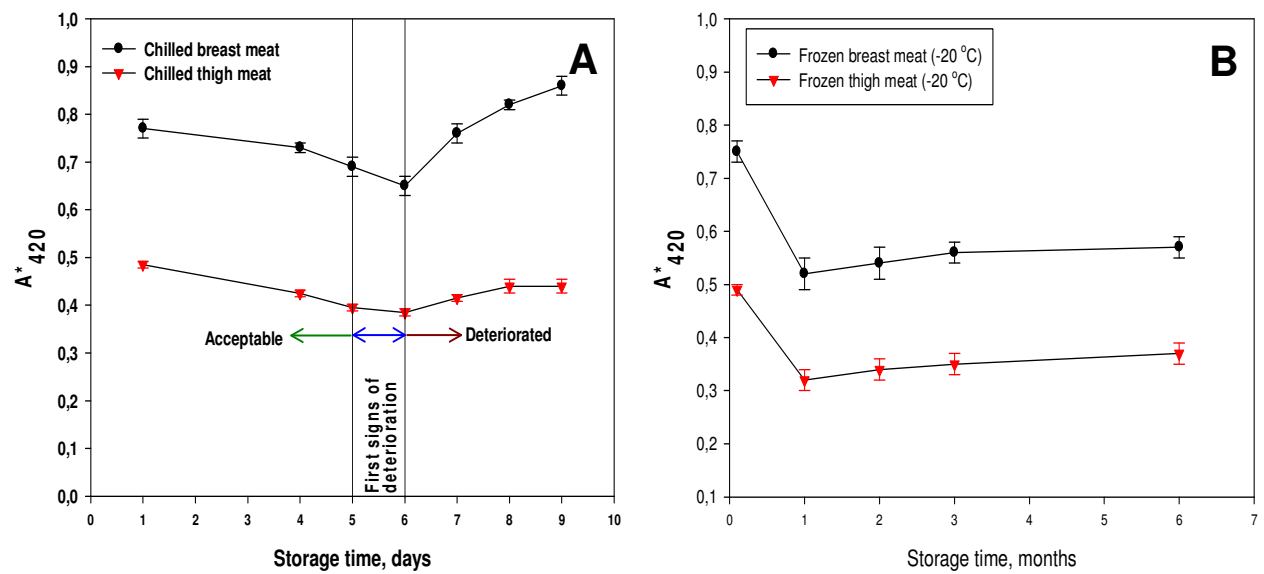

Figure 3. Changes in corrected absorbance values (A420*) of chilled-stored (A) and frozen-stored (B) chicken meat samples

This could be explained with the increased low molecular protein compounds content of long time chilled stored chicken meat, which were released as a result of the proteolysis in muscle tissue (Vassilev et al., 2012). Probably, these low molecular protein compounds are taking part in riboseinduced Maillard reaction and thus contributing to the increased A420* values. Slight increase in A420* after 6-th day of storage of chilled thigh meat was also found. After first month of frozen storage the A420* values of the studied samples marked slight increase, but remains significantly $(\mathrm{P}<0.05)$ lower in comparison with the chilled-stored samples. It could be assumed that the denaturation, aggregation and oxidation processes of chicken meat proteins resulting in decreased A420* values (Figure 3) are running mainly during the first 30 days of frozen storage. The increase of A420* after this period, is probably due to some protein defragmentation processes occurring in chicken muscle tissue (Vassilev et al., 2013).

The results from sensory evaluation indicated that chilled samples preserved good sensorial quality up to the 5-the day of the storage (Figure 3). Between 5-th and 6-th day of chilled storage first signs of deterioration were observed, making the chicken breast and thigh meat unacceptable for the consumers. Therefore, only the A420* values obtained up to the 6-th day of chilled storage were used for evaluation of chicken meat freshness as well as for differentiation of chilled and frozen-thawed meat. Frozen chicken meat

Vol. 18 (2014), no. 2 
samples preserved their sensory quality to the end of the experiment (6 month of frozen storage).

\section{Evaluation of the ribose-induced Maillard reaction rate}

Because of their dependence from the spectrophotometers characteristics, the A $420 *$ values are not reliable indicator for comparison of the ribose-induced Maillard reaction rate of different meat samples. This fact limits the application of $\mathrm{A} 420^{*}$ as meat quality index. For obtaining of comparable results for Maillard reaction rate a bovine melanoidin equivalent (BME) was used in the present study. On that purpose bovine melanoidins were isolated according to approved methodology (Authors Certificate № 34155, 1982, INRA, Sofia) and were used for preparation of the standard curve (Figure 2). By this approach the data for A420* were presented as $\mathrm{mg}$ BME/g meat sample and the results obtained are shown in Figure 4.

Application of BME as a measure for ribose-induced Maillard reaction rate enables comparability of the data obtained by different spectrophotometers. Presentation of the results as $\mathrm{mg} \mathrm{BME} / \mathrm{g}$ meat sample is expected to minimize the influence of meat chemical composition on the final results and thus will increase the reliability of the method.

Determination of threshold limit BME values for differentiation of chilled and frozen-thawed chicken meat

The changes in BME values during storage of chilled and frozen samples (Figure 4) had similar trends as the changes of A420* values. The results obtained indicated that BME values of chicken meat decreased significantly $(\mathrm{P}<0.05)$ during the first 30 days of frozen storage. The BME values of chicken meat frozen stored for more than 15 days were significantly $(\mathrm{P}<0.05)$ lower than BME values of chilled-stored samples. These results indicated the possibility for differentiation of chilled chicken meat from frozen chicken meat stored for more than 15 days.

Unfortunately, the BME values of frozen chicken meat during the first 15 days of storage did not differ significantly $(\mathrm{P}<0.05)$ from the $\mathrm{BME}$ values of chilled samples. On the basis of the results obtained in the present study (Figure 4) the following threshold limit values of BME for differentiation of chilled and frozen stored for more than 15 days chicken meat could be suggested: $30 \mathrm{mg} \mathrm{BME} / \mathrm{g}$ and $51 \mathrm{mg} \mathrm{BME} / \mathrm{g}$ for chicken thigh and breast meat, respectively.

Vol. 18 (2014), no. 2 

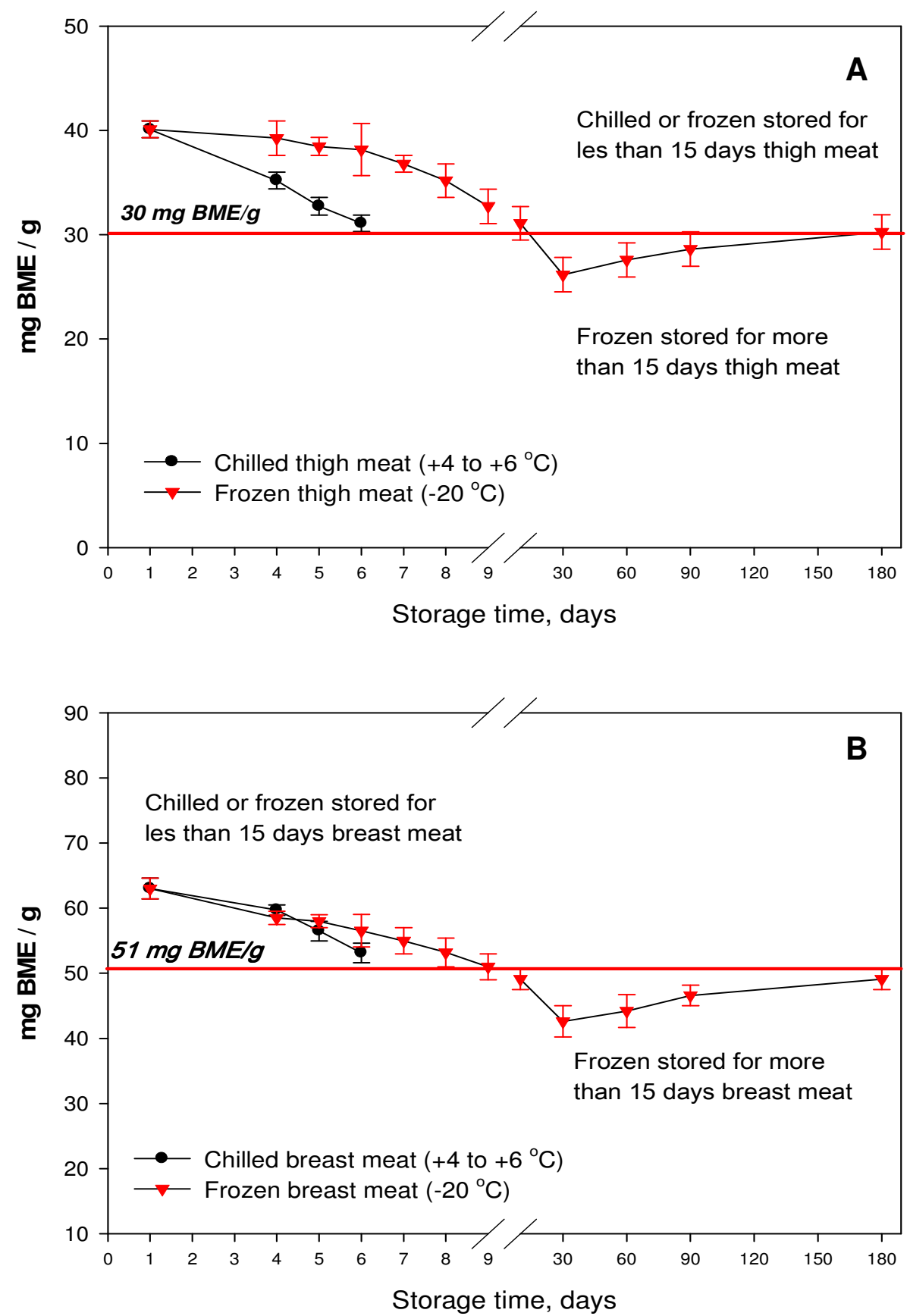

Figure 4. Changes in bovine melanoidin equivalent values (mg BME/g) during refrigerated storage of thigh (A) and breast (B) chicken meat samples

Vol. 18 (2014), no. 2 
According to these limits, the chicken thigh and breast meat with BME values lower than $30 \mathrm{mg} \mathrm{BME} / \mathrm{g}$ and $51 \mathrm{mg} \mathrm{BME} / \mathrm{g}$, respectively could be classified as frozen-thawed. For the practical implementation of the proposed threshold limit values, further investigations with different batches of chicken meat from different producers are needed.

\section{CONCLUSIONS}

The muscle type has significant effect on the ribose-induced Maillard reaction and has to be considered when using for meat quality evaluation. Application of BME as a measure of ribose-induced Maillard reaction rate enables comparability of the data obtained by different spectrophotometers and from different laboratories. It was found that, the BME values of chicken meat frozen stored for more than 15 days were significantly $(\mathrm{P}<0.05)$ lower than BME values of chilled-stored samples. These results indicated the possibility for differentiation of chilled chicken meat from frozen chicken meat stored for more than 15 days. For the practical implementation of the method further investigations on the effect of muscle type and meat physicochemical characteristics on the BME threshold limit values are needed.

\section{REFERENCES}

1. AOAC (1980). Official methods of analysis (13th ed.). Washington D. C.: Association of Official Analytical Chemists.

2. Ballin N.Z. and R. Lametsch (2008). Analytical methods for authentication of fresh vs. thawed meat - A review. Meat Science,80, 151-158. DOI: 10.1016/j.meatsci.2007.12.024.

3. Bligh, E. and Dayer W (1959). A rapid method of total lipid extraction and purification. Canadian Journal of Biochemistry and Physiology, 37, 911 - 917. DOI: 911-917, 10.1139/o59-099

4. Draper, N. and Smith, H. (1998). Applied regression analysis. 3rd edition. New York: John Wiley.

5. Farrant, J., Walter, C. A., \& Armstrong, J. A. (1967). Preservation of structure and function of an organized tissue after freezing and thawing. Proceedings of the Royal Society of London Series B Biological Sciences, 168(1012), 293-310. DOI: 10.1098/rspb.1967.0067

6. Jeremiah, L.E. (1996). Freezing effects on food quality. New York: Marcel Dekker.

Vol. 18 (2014), no. 2 
7. Kenward, M (1987). A method for comparing profiles of repeated manuscripts. Appl. Stat., 36, 296-308.

8. Korkeala, H., Maeki-Petaeys, O., Alanko, T., Sorvettula, O. (1986). Determination of $\mathrm{pH}$ in meat. Meat Science, 8 (2), 121-132. DOI: 10.1016/0309-1740(86)90088-4.

9. Martino, M. N., \& Zaritzky, N. E. (1988). Ice crystal size modifications during frozen beef storage. Journal of Food Science, 53(6), 1631-1637. DOI: 10.1111/j.1365-2621.1988.tb07802.x.

10. Obretenov Tzv., Ch. Krachanov M. Kuncheva, G. Somov, Sn. Ivanova, M. Obretenova (1982). Authors Certificate № 34155, Sofia: INRA.

11. Obretenov, D. Tzv., Sn. D. Ivanova, M. J. Kuntcheva and G. T. Somov Melanoidin Formation in Cooked Meat Products. J. Agric. Food Chem., 1993, 41(4), 653 -656. DOI: 10.1021/jf00028a028.

12. Šimoniová A., Rohlík B.-A., Škorpilová T., Petrová M., Pipek P. (2013). Differentiation between fresh and thawed chicken meats. Czech J. Food Sci., 31, 108-115.

13. Tan, T.-C., Alkarkhi, A.F.M. and Easa, A.M. (2012). Characterization of the ribose-induced Maillard reaction in minced chicken and minced pork: A potential means of species differentiation. Int. Food Res. J., 19, 481-489.

14. Tan, T.-C., Alkarkhi, A. F.M. and Easa, A. M. Ribose-Induced Maillard Reaction as a Quality Index in Frozen Minced Chicken and Pork Meats (2013). J. Food Quality, 36: 351-360. DOI: 10.1111/jfq.12041.

15. Vassilev, K., G. Ivanov, D. Balev, A. Bogdanova (2013). Effect of superchilling treatment and storage conditions on the proteolysis of chicken meat. In Scientific Works of UFT: International Scientific Conference "Food Science, Engineering and Technologies, 18-19 October 2013 (pp. 293-298). Plovdiv, Bulgaria: University of Food Technologies.

16. Vassilev, K., G. Ivanov, D. Balev, G. Dobrev (2012). Protein changes f chicken light and dark muscles during chilled storage. Journal of EcoAgriTourism, 8 (2), 263-268.

Vol. 18 (2014), no. 2 